\title{
根基与滋养：UIC国情国学教育的理念和实践
}

\section{Foundation and Nutrition: The Idea and Practice of UIC's National Education on Chinese Culture and Society}

\author{
伍鸿宇 Wu Hongyu*
}

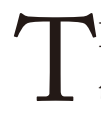
HERE are numerous skills that students need to learn during their time at university, in addition to thinking about the construction of self-identity and the meaning of life. UIC's National Education on Chinese Culture and Society (NECCS) aims to help students cultivate their sentiments and think about the future direction of life.

This paper is divided into two parts. The first part explores the following question: Why does UIC carry out the NECCS? In this part, three ideas are introduced: First, the state and individual are connected. Every country has its own history, traditions and social systems that impact the way a person grows up and are closely related to the life paths that person may take. The establishment of UIC is a response to China's higher education reform and social needs. Second, tradition is integrated into our life. Cultural tradition exists not only in history books, but also in our blood and our way of thinking. Cultural heritage is of great value to individuals, countries and the world. Third, China participates in the common development of the world. Through comparative observation between China and the world, students can reflect on their habitual lifestyles and values, and thus we can help them to understand cultural phenomena from the perspective of history and globalisation, and think about how to live in the new era.

The second part discusses the following question: How do we promote the NECCS? This part introduces how UIC is committed to

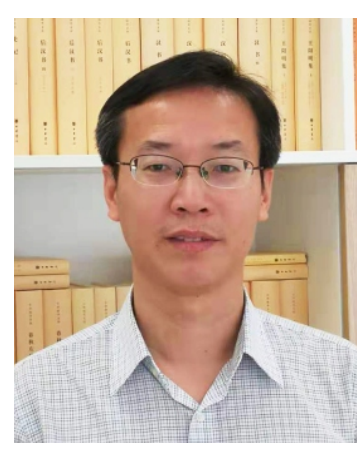

* 伍鸿宇教授是北师港浸 大中国语言文化中心主 任、中华文化传播研究 院秘书长。

Professor Wu Hongyu is Director of UIC's Chinese Language and Culture Centre, and SecretaryGeneral of the Research Institute for Dissemination of Chinese Culture. 
innovative education concepts and methods. It includes three aspects: curriculum designs that advocate speculation and reflection, seminars that focus on the development of teaching and learning, and cultural activities that promote creative inheritance.

In short, the mission of UIC's NECCS is to promote the inheritance of traditional Chinese cultures and to contribute to the growth of UIC's students.

在大学阶段, 学生不仅需要学习技能, 还应该思考自我身份的建构和人生的意义。 UIC的国情国学教育旨在帮助学生陶养情操, 思考未来的人生方向。本文分为两个部分。第 一部分探讨的问题是: UIC为什么推行国情国学教育? 由此引出国情国学教育的三种理念：首 先, 我们与国家血脉相连。每个国家都有特定的历史传统和社会制度, 每个人的成长道路都 是与国家的命运和发展息息相关。UIC的创建也是对中国高等教育改革和社会需要的回应。 第二, 传统融入我们的生活。文化传统不仅存在于在历史书里, 更是融入生命的血液中和我 们日常的思维方式中。文化传承对个人、国家和世界都具有重大价值。第三, 中国与世界融 合发展。透过中国与世界的相互对比观察, 让学生反思自身以及习以为常的生活方式和价值 观, 帮助他们从历史的、全球化的角度看待文化现象, 思考在新时代应当如何生活。第二部 分探讨的问题是：如何推动国情国学教育? 这部分介绍了UIC如何通过多元的教学和研究来 创新教育的途径与方式, 具体包括三方面: 课程设计倡导思辨, 研讨会注重教学相长, 文化 活动促进传承出新等。简言之, UIC的国情国学教育希望为传统文化的薪火相传和UIC学生的 成长贡献力量。

\section{引言：书是读不完的，更重要的是人生的 方向}

新学期, 新开始。UIC的校园活跃着一批 满脸朝气和好奇的年轻学子。新生们期待已 久的大学生活就要开始了, 怎能不兴奋呢? 在即将展开的大学四年, 他们一定会经历各 种各样的生活场景, 第一次登台做报告的紧 张不安, 截止时间前完成课题的如释重负, 和志趣相投的朋友聊天时的舒畅快意等等, 大学生活忙碌而充实。但是, 随着知识的积
累, 时间的流逝, 他们也一定会萌生各种困 惑: 追求自由和个性的同时如何建构自己的 身份认同? 全球化的时代如何面对自己的文 化传统? 作为大学生, 生命的目标与意义何 在? 作为中国人, 安身立命的根基在哪里?

“风声雨声读书声声声入耳, 家事国事 天下事事事关心”。千百年来中国的知识分 子就是以天下为己任, “达则兼济天下, 穷 则独善其身”。读书的目的不仅是为了个人 的自由与幸福, 更是为了天下苍生的福祉。 所以, 书本上的知识是学不完的, 而学生在 


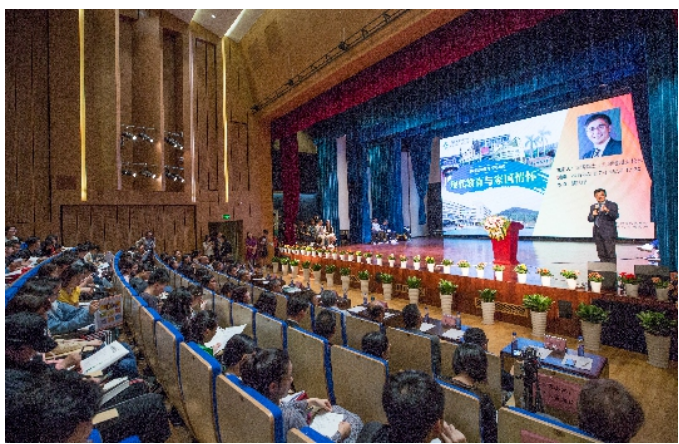

汤涛校长的 “开学第一课”

大学阶段需要明确人生的方向。UIC的校训 是 “博文雅志, 真知笃行”。其含义就是希 望学生“博学于文”, 广泛涉猎人文、艺 术、社会和自然科学等一切有用的知识, 由 此陶养情操, 培育志向, 完成人格精神的内 在建构, 这是新时代博雅教育的育人旨归, 也是UIC学子成人成才的必然要求。正如汤 涛校长在开学典礼上所说的, “汲取中国传 统智慧，掌握现代科技知识。”作为UIC博 雅教育的重要组成部分, 国情国学教育由此 而来, 其初心与使命, 就是帮助学生扎根历 史土壤, 在丰富的文化滋养中, 让求知、求 真的生命活泼起来, 丰厚起来, 成熟起来。

\section{一、为什么推行国情国学教育?}

中国走怎样一条发展道路, 是由国情决 定的, 而中国人如何走这条道路, 国学中所 蕴含的传统文化基因又起着巨大的影响。中 国人民能不能探索出一条适合于自身发展的 道路, 取决于国人对于国情的认识水平, 以 及深厚国学根基的承托。传统文化的深厚资 源与思想政治教育应是互渗相融的关系, 这 种相融不是理论的空谈, 而是要体现在新的 教学理念的实际建构上。

\section{1. 我们与国家血脉相连}

在今天这个高度信息化、全球化的时 代, 家国情怀对于青年学子意味着什么? 可 能很难有一个准确的答案。每个国家都有特 定的历史传统和社会制度, 每个人的成长道 路都是与国家的命运和发展息息相关。正如 习近平主席指出的，“每个人的前途命运都 与国家和民族的前途命运紧密相连。国家 好，民族好，大家才会好。”

对每一个中国人来说, 虽然我们可能习 焉不察, 但是我们身上总以或隐或显的方式 携带着传统文化基因。历史的烟云告诉我 们, “没有国, 哪有家, 没有家, 哪有 你”。国家有危难时, 身为中华儿女的我们 无法置身事外，而那些对家国抱着一腔热血 与赤诚的中国人更令我们肃然起敬: 战争的 烟火曾经让华北放不下一张安静的书桌，一 批知识分子投笔从戎; 科学家钱学森冲破重 重阻碍, 毅然决然地回到祖国投身建设; 电 影《无问西东》里富家子弟沈光耀驾驶战 机冲向敌舰, 为保家卫国献上自己最灿烂的 青春。

“我们都有一个家, 名字叫中国。”对 于那些远在异国他乡遇到危难的中国人来 说，他们也格外清晰地感受到国家对公民的 保护和意义。以近年来中国海外撤侨行动为 例, 2011年利比亚局势动荡不安, 战争一触 即发, 为了保证当地华侨能够平安回国, 中 国政府动用了91架次中国民航包机，35架次 外航包机, 12架次军机, 租用外国邮轮11 艘, 国有商船5 艘, 军舰1艘, 用了12天将 3万多名包括港澳台同胞在内的中国驻利比 亚人员成功撤离。在记者的报道中, 现场的 一位同胞留着泪感慨说, “感谢祖国的强 大，让自己可以有这样一个温暖的家。没有 
和平的年代, 只有和平的国家”。与此类 似, 也门撤侨, 尼泊尔撤侨, 新西兰撤侨等 等, 每一次行动都是惊心动魄的救援。

UIC 的成立正是中国教育改革潮流中的 产物, 它是中国内地与香港合作创办的第一 所高校。香港回归后, 教育部很快出台了相 关新政, 促进内地与香港的教育合作。 1999年, 教育部发布了《关于开展内地与香 港教育交流若干问题的意见》，2001年又公 布了《关于教育交流事宜会谈纪要》, 2003年国务院正式颁布《中外合作办学条 例》。正是在这样的政策推动下, 许多有识 之土积极开辟新的教育试验田, 力图通过两 地的交流与合作, 助推中国高等教育的健康 发展。2005年, 在许嘉璐先生的支持下, 北 京师范大学和香港浸会大学在珠海合作创立 了UIC。

在创建之初, UIC面对着办一所什么样 的大学来回应中国高教改革和社会需要? UIC 的开创者们认识到, 在教育全球化的时 代，在教育方式、理念和资源充分国际化的 同时, 也必需回应本土的、民族的和国家的 社会发展需要。作为一所在中国历史发展新 进程中创建的新型大学, UIC要培养既具有 国际化的眼光和能力, 又有中国根基的高素 质人才。一个合格的世界公民, 必须是一个 优秀的国家公民。

\section{2. 传统融入我们的生活}

传统离我们有多远? 被高新科技所包围 的现代人很难静下心来问自己这个问题。但 是, 当你拿起一本历史著作, 或者走进一家 历史博物馆, 你就会回到似曾相识的场景 中。例如, 当我们走进国家博物馆, 在中国
古代历史文化的展厅里，一件件文物既令人 惊叹, 又让人倍感亲切。看到三千多年前殷 商时期的甲骨文, 普通人也能大致猜出几个 字; 面对汉代的说唱陶俑, 我们不禁对古人 的娱乐形式会心一笑; 驻足于唐代骆驼陶俑 前, 我们眼前不禁浮现出当年文化交流的盛 况来。这些文化传统对于我们, 不仅存在于 历史书中, 更是融入生命的血液里和日常的 思维中。

如果一个人拥有无数的珍宝, 却视而不 见, 整天做着发财梦, 你不觉得他实在是愚 春吗? 面对中华文化的资源宝库, 所有的炎 黄子孙都是天然的继承人。今天的中国人尤 其需要通过传承和创意, 让这些传统焕发出 新的生机, 体现出现代生活价值来。

\section{（1）文化传承对个人的价值}

上这些中国文化课有什么用? 总是会 有学生提出这样的问题。越是物质高度发达 的时代, 人们越是难逃功利化的宿命, 有用 与无用也就成为人们评判事物价值的标准。 可惜的是, 不少人理解不了 “无用之用乃为 大用”的境界, 对每一个现代人而言, 物质 世界与精神世界同样重要。例如, 忙碌是现 代人的通病, 如何在忙碌的现代生活中过一 种诗意的生活呢? 2010届社会工作与社会 行政学毕业生谢晓雪, 曾经如此描述她在 UIC读书时的状态: “我们都已经很忙。路 上碰见同学也是随便点个头就过, 所谓休闲 不过是在小餐馆里吃一顿犒劳自己的饭菜, 倚在沙发垫上眯着眼晒一会太阳, 嘴里还在 不停地讲着活动企划, 脑子里还在想那个电 脑程序要怎样修改。”生活真的需要如此疲 急吗? 阅读中国文学作品带给她这样的 思考: 
让我们把陶沸明也放进备忘录里吧。陶 渊明说: “凯风因时来, 回㣏风开我襟, 息交 游闲业, 卧起弄琴书。”在路上勿勿而过的 时候, 略微留意一下吹动衣襟的和风, 留意 一下路边开放的野花，留意一下熟识的朋友 打招呼时的笑脸; 把生活用这一种方式沉淀 下来, 把忙碌的渣滓都撇清, 认识自己到底 在忙碌些什么。用陶渊明的悠闲和清净洗涤 自己的生活。( 《让我们把陶渊明也放在备 忘录里》)

文化传承可以有多种形式，对个人的价 值也会有多种体现。对2015届电影电视学毕 业生刘訢然来说, 中国文化与自己的职业发 展紧密地联系在一起。她从UIC毕业后赴澳 大利亚悉尼大学读研, 回国后成为广东广播 电视台国际频道访谈栏目《Face Time面对 面》的编导、主持人。通过对中外文化的真 实体验, 她的理想就是要在文化交流中讲好 中国故事。

而对每个中国人来说，无论有着怎样的 职业兴趣, 修习中国文化经典, 既可以养气 志、增学识, 还可以促感兴, 丰富人的内在 情怀和提升心灵境界。正如习近平主席所 言, “学史可以看成败、鉴得失、知兴替; 学诗可以情飞扬、志高昂、人灵秀。”

\section{（2）文化传承对国家的价值}

“观乎天文以察时变，观乎人文以化成 天下”。中国是一个非常注重文化传统的国 家, 千百年来无论中国大地如何遭遇外来冲 击或者改朝换代, 只要中华文化的脉络没有 断, 中国历史总能开出一片新的天地来。即 使一时遭遇“亡国”，也绝不会“亡天 下”。中华文明之所以能成为世界历史上少
有的, 延续至今且没有断层的文明, 可以 说，文化传统起到了核心的作用。

对于一个民族和国家来说，失去自身的 文化传统意味着什么呢? 法国作家都德在他 的短篇小说《最后一课》中描述过这种情 形。生活在法国阿尔萨斯省的一个小镇上的 小学生弗郎士经常逃学。一天早上, 他到了 学校, 老师韩麦尔先生告诉他们这是最后一 堂法文课。原来战败的法国被迫将阿尔萨斯 和洛林割让给普鲁士, 而普鲁士禁止这两地 的学校教授法语。小弗郎士猛然感觉到再也 不能学习祖国语言是何等的悲哀! 这篇小说 生动地写出了文化传统对一个民族的特殊意 义, 即使是一个原本无忧无虑的顽童, 失去 了这种文化权利也会受到强烈的震动。

因此，习近平主席说，“一个国家、一 个民族的强盛，总是以文化兴盛为支撑的。 没有文明的继承和发展，没有文化的弘扬和 繁荣，就没有中国梦的实现。中华优秀传统 文化是中华民族的突出优势，中华民族伟大 复兴需要以中华文化发展繁荣为条件，必须 大力弘扬中华优秀传统文化。”这段话充分 说明了文化传承对一个国家的重大意义。如 果一个国家的教育不能够珍视和尊重自己本 民族的文化的传统，构建本民族的精神生活 空间, 就无法延续历史文脉, 更无法形成生 生不息的文化的生命力和创造力。

\section{（3）文化传承对世界的价值}

当今世界已不同于历史上任何一个时 期, 全球化的触角已深入世界的每一个角 落, 没有哪一种文化的传承和传播可以置之 度外。随着中国综合实力的显著提升, 中国 文化在世界舞台上的地位越来越重要。中华 文化源远流长, 它不仅是今天的中国人安身 


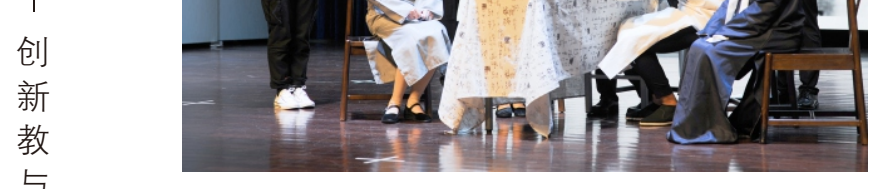

在中国文化创意大赛上, 学生演出《山雨欲来风 满楼》, 再现了辉煌的建党历程

立命的根本, 还可以为当今世界解决全球性 问题提供重要思想和智慧。例如: 天下观与 全球治理; 天人合一与全球生态; 和而不同 与国际关系; 自强不息与民族崛起; 仁爱精 神与人伦道德等等。其中, 天人合一思想是 中国传统哲学的重要特色, 是东方综合思维 模式的完整体现。面对当今的生态危机, 有 不少学者认为儒家思想以天人合一为根基, 主张爱物成物, 取之有时, 用之有度, 所谓 “必有以知天地之恒制, 乃可以有天地之成 利”, 包含着丰富而独特的生态思想, 与生态 文明深度契合, 是深化和发展这一理论的宝 贵资源。

正如美国作家、诺贝尔文学奖得主赛珍 珠所言:

今日中国的青年人不再接受孔子智慧的 教育……这个国家的人对孔子已不再熟悉, 他 (孔子) 在十几个世纪前花毕生精力从混 乱中创造秩序, 从不道德中创造道德来拯救 它。他的话是永存的, 因为它们是真理, 真 理总有一天要胜利的。会有那么一天, 孔子 将回到他自己的国家。……他的话在这里照 亮了一个美国人的心，它们成为我存在的一 个部分。(《中国：过去和现在》)

\section{3. 中国与世界融合发展}

古代中国从来没有停止过迈向世界的步 伐。正如梁启超先生所言: 从黄帝到秦朝, 是中国之中国; 从秦朝到清朝, 是亚洲之中 国; 从清朝到近代, 是世界之中国。从张寒 業空西域, 到郑和七下西洋, 中国与世界曾 经联系紧密。遗憾的是, 近代以来中国与世 界的距离逐渐拉大, 几度错失了融入世界的 历史机遇。经过百余年的艰难探索, 经过新 中国70年的发展, 特别是 40 多年的改革开 放, 中国国际地位日益提升, 中国文化逐渐 走出了近代以来备受冷落和质疑的命运。于 是, 一部分人变得盲目自大、过于自信, 以 为全世界的问题和全人类的未来都掌握在中 国人手里; 而另一部分人无法摆脱文化自 卑, 骨子里依然崇洋媚外, 以为中国社会的 出路需要西方文化的引领。这些现象产生的 根源纷繁复杂, 其中一个基本原因是, 他们 对中国与世界的关系缺少全面的认知, 尤其 是不能从世界历史发展的脉络来认识中国, 也不能从中国社会发展的历程来认识世界, 而是将中国与世界割裂开来、对立起来。

正如习近平主席所说的, “世界好, 中 国才能好; 中国好, 世界才更好”。国情国 学教育需要为学生树立中国与世界融合发展 的观念。通过古与今的纵向梳理、中与外的 横向拓展, 以国情关怀激励国学研读, 以国 学根基深化国情思考。通过诠释、研讨中国 古代的思想和文化, 帮助学生在深刻理解中 国历史文化的基础之上, 对当今中国社会和 世界格局有更深的理解和认识。培养学生不 局限于一隅或单向度地思考问题, 而是从宏 观的、全球化的角度看待世界。所以, 国情 国学教育强调在教学中开放心胸, 超越不同 的空间、不同的社会制度、不同的传统, 将 
古今中外人类的经验融合在一起, 开阔学生 的眼界。

综上所言, UIC的人才培养目标是学生不 仅要有国际化的眼光和能力, 也要有本土性 的知识和素养。UIC的国情国学教育的构想 就是面向整个民族的历史与未来。国情国学 教育致力于培育学生“情系家国、心怀天 下”的品格。就是希望增进学生对国家与民 族的认同与热爱, 增强学生的使命感和责任 意识, 激励其自觉承担社会责任, 立志为民 族发展贡献力量, 并能立足中国立场认识世 界，基于全球视野审视中国。

\section{二、如何推动国情国学教育?}

在上述教育理念之下，国情国学教育致 力于创新教育途径与方式, 建构融合核心课 程、教学研讨、系列讲座、文化创意、社会 调查为一体的多层次教学模式。

\section{1. 课程设计倡导思辨}

经过多年的探索和改革, 我们设计了三 门核心课程, 从文史哲等不同的向度出发, 帮助学生陶冶思想情操, 培养思辨能力, 开 阔知识视野。这三门课程的名称是《大学国 文》《中国社会思潮》和《中国历史与文明 专题》。

《大学国文》是国情国学教育中彰显赏 析和陶冶的部分。学习语言文学是在审美的 过程中育德性、养情怀、启智慧、展辞采, 由此成就文质涁涁的“君子”。通过学习 “文学与生活”的传统, 以文学的光彩化育 心灵, 促进学生的全面发展。《论语》中有 “诗可以兴、可以观、可以群、可以怨”的
说法, 感发意志, 相互切磋, 正是批判性思 维、内在情感与心性的教育。课程的设计不 仅是提升学生的语言能力, 而是借助文学中 情与理, 价值取向与人生感悟向读者的心灵 传递着生命的温度, 通过赏析作品来培育人 与成就人, 其中的丰富审美情感, 涵养内在 心性, 达成精神层次的提升与人格的完善。

《中国社会思潮》是国情国学教育中突 出多元和思辨的部分。其内容主要介绍中国 两个时期的思潮：一是先秦时期的诸子百家 思想，二是从1840年鸦片战争一直到改革开 放的进程中涌现出的各种思想。该课程着眼 于分析 “传统与现代”之间的联系，兼顾了 中国古代哲学与现当代的革命思想。在层出 不穷的观点和纷纭复杂的现象面前, 我们希 望帮助学生汲取传统文化中的思想资源, 通 过阅读、思考、讨论、辨析, 批判地继承和 借鉴前人丰富而深刻的思想成果; 在了解中 国传统思想精髓的同时, 还能够用思想理论 来分析和解决现实社会问题, 能积极主动地 对国家政治与社会发展展开深入思考。

《中国历史与文明专题》是国情国学教 育中突出对比和反思的部分。在教学中, 我 们将中华文明的进程放在纵向的历史脉络和 横向的世界发展图景之中进行对比。一方面 梳理中国文化的发展如何随着时代而改变, 同时展示世界其他地区的文化特点与成就， 帮助学生了解中外文明的发展脉络, 开阔学 生视野。该课程着眼于对照 “中国与世界” 的异同, 以文化专题形式介绍中国传统生活 方式、讲述文化发展与演变, 同时也比较了 不同社会脉络中文化发展的异同之处。其目 的在于帮助学生理解各种文化现象, 并以开 阔的视野思考社会议题。在深入文化本质的 同时, 培养学生多元思考和批判性思维 能力。 


\section{2. 研讨会注重教学相长}

国情国学教育的目的在于帮助学生对国 情国学的认知和反思, 教育不是为了教育而 教育, 而是着眼于培养真正了解社会传统和 现实的公民。要让教学从传统的课堂模式上 走出来, 师生以知识为载体进行相互交流、 相互启发、相互提升。国情国学教育需要在 课程内容上做出探索, 这些课程在内容上将 回归到中华民族最根本的层面上去, 面向整 个历史和民族的未来发展。

为了实现这样的目标, 我们以课程为中 心, 每学期都举办面向我校学生的“国情国 学教学研讨会”。它是在香港与内地合作办 学的新机制下, 传扬古学风, 激发新思想, 特意打造的一个开放、自由的学术交流平 台。研讨会迄今已举办 23 届, 成为 $U I C$ 一个 重要的教学传统。其内容主要包含五个主 题: 一是“回溯历史”, 例如, 对一种传统 ( 书院教育) 、一部著作 (黄宗羲《明夷待 访录》) 和一段历史 (抗日战争) 进行了梳 理与思考; 二是 “反思传统” , 探讨的是中 国的文学经典、传统思想和生活方式与现代 生活的联系, 传统如何融入现代, 而现代又 怎样传承传统的话题; 三是“透视热点”, 从多元化视角展开对两岸关系、钓鱼岛问题 和一带一路倡议的讨论; 四是“融通中 西”，从文学经典、中西文化交流和全球化 时代的中华文化三个层面做出阐述; 五是 “面向未来”，在这一主题下回顾了辛亥革 命、百年教育、城市与海的历史, 在学习历 史经验的同时, 反思当下的得失并且建构 未来。

国情国学教学研讨会既是对中国传统书 院精神的一种传承, 也是爱国主义教育和国
情教育一个创新的实践。它既促进学术的发 展, 又成为课堂教学的重要延伸和补充。通 过这个平台, UIC邀请海内外的许多知名专 家学者走进校园, 给师生们带来了理论视角的 观察, 学术前沿的声音, 为UIC 的博雅教育 提供了丰沛的精神滋养。

\section{3. 文化活动促进创意出新}

UIC的教育理念重在激发学生对传统文 化的深入思考与创意, 而非被动接受, 因此 与课堂教学相配合, UIC还举办文化创意大 赛、创意征文、创意 $D V$ 大赛等。以一年一 度的中国文化创意大赛为例, 它是由课堂向 课外延伸的一种创意教学。在课程学习中, 各专业的学生按照个人志趣, 由五六人自由 组成学社。学生们在课堂学习国情国学知识 的基础上, 将自己对中国文化历史的反思, 对当代社会焦点问题的关注, 以舞台短剧的 形式展现出来, 极大地锻炼了学生的创意 才能。

例如，在2019年第14届中国文化创意大 赛中, 媒体艺术与设计专业的三字学社表演 的作品是《止楚攻宋行兼爱》, 取材于战国 时期墨子成功阻止楚国攻打宋国的故事。大 二新闻学专业明月社的原创作品《医馆》讲 述了在二十世纪初的中国, 西风东渐, 闽东 小镇中医馆传人刘聪在女西医玉林的启发 下，立志学习西医的故事。

每次大赛我们都会邀请社会各界文化名 人担当评委, 他们对学生的创意表演给予了 相当高的评价, 例如:

作家韩少功说: 大赛很好, 很有创意。 大学生就应该 “活学文化”, 多锻炼, 不要 死读书, 这对我们传统文化的传承很有帮 
助, 再精彩的讲课也不如自己动手。这个大 赛的方式很好，尤其舞台是一门综合艺术， 要同时调动很多技巧。所以我希望大家有机 会就要多多实践。

珠海电视台总编辑殷亚敏说: 《霍小玉 传》这个节目, 用传统皮影的形式演绎了一 段历史传奇, 真是别开洞天。中国流落在民 间的传统艺术, 通过今天晚上我们能明显的 感觉到一种传承。皮影戏的难度是非常大 的, 我刚才特地注意了一下, 表演皮影的同 学既要控制皮影, 又要顾及台词, 真是很不 容易。但是难度这么大, 他们还是可以表演 的如此栩栩如生, 可见皮影戏后继有人啊!

中国文化创意大赛不但成为校园中的文 化风景, 而且引起了《澳亚卫视》、《新世 纪周刊》、《新周刊》、《大学生》、香港

《文汇报》、《珠海特区报》等媒体的关注 和报道。

此外, 国情国学教育还希望丰富教育途 径、打破单一教学局面。每年寒暑期组织的 游学营活动是国情国学教育体验式教学的一 种探索。游学营由专家教授带队, 以游学的 形式，走访名胜古迹、考察民风民俗，亲身 感受文化魅力。主要活动除了聆听知名学 者、作家或文化名人的讲座之外，学生也有 机会参访不同的大学并与当地的学生进行对 话与交流。当然, 参观博物馆、名人故居、 文化景点和感受自然风光也是重要的内容。

其中，以传播和学习国学为主的“国学 营研习营”举办过多次, 分别是庐山国学 营、齐鲁文化国学营、江湖国学营、中原文 化国学营, 以及阳明国学营等。学生在跟随 名师研习学问的过程中, 不仅游览风景名 胜, 凭吊历史文化名人，更学会用批判的思 维，传承民族传统，弘扬中华文化，延续文
化的命脉与精髓。2011届政治与国际关系毕 业生杨怀智对此感言:

对我们而言，平日多被某些“现实”的 目标局限于一个狭险的环境之中，琐碎而庸 碌。看多了功利的人，想多了世俗的事，很 需要有那么几天, 跳脱出这拥堵的环境, 在 一个漫长而辽阔的时空中来重新审视自我, 观察世界。寻往圣之足迹, 发思古之幽情, 与天地精神相往来。( 《江湖国学营》)

其实学生有此“感”, 才能有所 “兴”。国情国学教育希望通过丰富多元的 教学实践帮助学生变被动接受为主动参与, 充分调动学生的积极性与自主性, 在亲身实 践、多方体验中, 增强思辨能力、审美能力 和创意能力。这样课本中的清词丽句、审美 情怀才能在他们的心中生动起来, 融入到他 们自身的精神建构中去。

\section{结语}

教育的根本目的不是技能训练、也不是 灌输知识，而是要让生命获得尊重，焕发 出光彩。“罵飞鱼跃”是古代大儒们崇尚 的气象：鸟在天上飞，鱼在水里游，显示 出一种活泼的精神，这是大自然的精神， 也是君子应该具备的精神。只有全面发展 的自由生命才能继承和创造灿烂的文化， 也只有立足于坚实的大地，在深厚的文化 滋养中，生命才有真正的源头活水。“路 漫漫其修远兮"，在国情国学教育的路 上，我们将以生命为本，文化为根，薪火 相传，为传统文化的生生不息，为个体生 命之树的成长而持续耕耘。亚 